\title{
Fundamentals of Airway Surgery, Part I
}

Editors

JEAN DESLAURIERS

FARID M. SHAMJI

BILL NELEMS

THORACIC

SURGERY CLINICS

www.thoracic.theclinics.com

Consulting Editor

M. BLAIR MARSHALL

May 2018 • Volume 28 - Number 2 